\title{
EFICIENCIA ENERGÉTICA, LA NECESIDAD DEL SIGLO XXI, DE CRISTIÁN HERMANSEN Y OTROS*
}

\section{Eduardo Esperguel Galaz}

Al pensar en un título para un libro que trata sobre Eficiencia Energética (EE), no logro encontrar uno mejor que el dado por los autores a esta obra: Eficiencia Energética, la necesidad del siglo XXI. El título sitúa de inmediato al lector en un plano de atención especial, diferente, otorgando a la EE la categoría de necesidad para la época en desarrollo. No obstante lo anterior, es importante señalar que no estamos frente a un libro que entregue una argumentación exhaustiva acerca de la importancia de la EE en el intento de sortear las dificultades que presenta el escenario energético actual -nacional e internacional-, sino más bien centra su esfuerzo en dar a conocer los principales aspectos asociados a la implementación de medidas concretas relacionadas a conseguir un mejor uso de la energía, por lo que se puede afirmar sin inconvenientes que se trata de un texto con fines prácticos más que teóricos. Esto resulta de mucha importancia para que un potencial lector de corte más académico no resulte desilusionado, y, por otro lado, para motivar a aquellos lectores que, motivados por su curiosidad o necesidad, se encuentran en búsqueda de una referencia práctica sobre el tema, lo que no resulta sencillo de conseguir.

A lo largo del libro, los autores dan a conocer una serie de conceptos relevantes asociados a la EE, los que, a pesar de su complejidad, son debidamente contextualizados y explicados en forma breve y sencilla, de modo de facilitar la comprensión de lo que se expone, y no complicando esta más de la cuenta. Esto devela rápidamente al lector la intención, por parte de los autores, de promover la EE como una práctica cotidiana, exponiendo ejemplos de la vida diaria, tanto laboral como doméstica, toda vez que se hace hincapié en la necesidad de generar un cambio cultural respecto del uso de la energía en los tiempos que corren -y los que vendrán-, buscando concientizar al lector del rol que le corresponde jugar a cada uno de nosotros, y no solo a aquellos que ostentan un cargo público o de importancia.

En cuanto a su estructura, el libro consta de 10 capítulos bien definidos cada uno de ellos y complementarios entre sí. De esta forma, en la medida en que avanzan las páginas se van introduciendo paulatinamente más elementos que se deben considerar para llevar a cabo medidas de EE, desde los conceptos más básicos de la física que sustenta los procesos en que se requiere utilizar energía, pasando por la forma correcta en que se deben evaluar económicamente las alternativas de mejoras en EE, hasta llegar a los conceptos de mayor elaboración aquí presentados, como son las Auditorías Energéticas (AE) y los Sistemas de Gestión Energética (SGE). Estos conceptos son presentados como los ejes de una política de EE en una institución, ya sea de carácter productiva o

* Hermansen, C. et al, Eficiencia Energética, la necesidad del siglo XXI, Santiago: Colegio de Ingenieros A.G, $1^{\mathrm{a}}$ ed., 2012. 
de servicios. Cada uno de estos conceptos es desarrollado en un capítulo completo, lo que da cuenta de su relevancia. A su vez, el concepto de SGE se encuentra íntimamente ligado a la aplicación de la Norma ISO 50001, de reciente publicación, la que también cuenta con un capítulo completo dedicado a su descripción y difusión.

Respecto del objetivo central del libro, es importante destacar que el enfoque que se da al tema es su aplicación en la industria y las actividades comerciales en general, más que las aplicaciones domésticas, aunque también son tratadas. Esto tiene relación con la importancia relativa del consumo comercial e industrial por sobre los consumos domiciliarios, además de tratarse de actividades más complejas desde el punto de vista del uso de la energía, de modo que se presentan mayores posibilidades de mejora en cuanto a EE.

Otra elemento destacable de esta publicación es la transmisión de consejos prácticos (know how) que se deben tener en cuenta para la aplicación de medidas de EE. Estos consejos resultan muy importantes a la hora de aplicar y dar permanencia en el tiempo a dichas medidas, puesto que normalmente tienen que ver con formas de relacionarse que redundan en un trabajo en equipo entre los trabajadores de una institución, los directivos de esta y los especialistas externos que asesoran una eventual mejora en los procesos que involucran el uso de la energía dentro de la institución. De igual forma, el énfasis que se da a la capacitación de las personas a todo nivel dentro de la institución, así como las reuniones permanentes y la conformación de equipos técnicos dentro de la misma, forman parte de un plan integral de aplicación de las medidas de EE que involucran a todos los integrantes del plantel, los que a su vez se permean de estas prácticas y conceptos y los van promoviendo en su entorno más cercano, contribuyendo así a la difusión de las buenas prácticas en el uso eficiente de la energía.

Finalmente, valorar el compromiso de los autores para con el tema, lo que se expresa en forma brillante en el último capítulo dedicado a las conclusiones y recomendaciones. Allí, los autores plasman su visión sobre la imperiosa necesidad de darle a este tema el carácter de política de Estado, por sobre las actuaciones particulares de gobiernos o ministros, proponiendo una concientización de la población por medio de la educación formal, tanto para la educación básica y media, como en las carreras universitarias que posean cierto grado de relación con la implementación de medidas de EE, dentro de las cuales se pueden mencionar las carreras de Ingeniería, Arquitectura, Construcción Civil, entre otras. Esto último resulta especialmente relevante para la futura aplicación de la EE en los distintos ámbitos del quehacer humano, de modo de procurar la búsqueda de los nuevos -buenos- equilibrios entre desarrollo económico, bienestar social y sustentabilidad ambiental. 